\title{
O TRABALHO EM PERSPECTIVA: IDENTIDADE E SUBJETIVIDADE
}

\author{
WORK IN PERSPECTIVE: \\ IDENTITY AND SUBJECTIVITY
}

Anne Marie Wautier*

RESUMO: O trabalho "moderno" foi construído no jogo de força entre dominantes e dominados e manifestou-se sob três tendências: a racionalidade econômica; a procura de integração normativa ao modo de produção capitalista mediante a instrumentalização dos trabalhadores; o surgimento de uma identidade operária por via da ação coletiva. A partir da segunda metade do séc. XX, aparecem novos modos de produção e de gestão que provocam mudanças significativas no mundo do trabalho em nível global. O trabalho e (ou) sua falta tornam-se objetos de insatisfação, até mesmo de sofrimento. $\mathrm{O}$ trabalho entra em crise. As mesmas tendências podem ser observadas no Brasil. Nos últimos trinta anos, desenvolvem-se formas variadas de trabalho informal, inclusive no campo da economia solidária, como forma de resposta ao "apartheid" social dos trabalhadores e à profunda fratura econômica da sociedade brasileira. A preocupação, neste artigo, é procurar saber em que medida o trabalho, hoje, pode construir o trabalhador como sujeito social e se tornar a experiência fundadora de identidade social e de ação coletiva, debate que abrange aspectos históricos, teóricos e empíricos.

Palavras-chave: identidade; subjetividade; experiência social; relação com o trabalho.

\footnotetext{
* Doutora em Sociologia, Professora no Instituto de Filosofia, Sociologia e Política da Universidade Federal de Pelotas; Pelotas (RS), Brasil, e-mail: anniewautier@yahoo.com.br
} 
ABSTRACT: The work "modern" was built in the game of power between dominant and dominated and manifested itself in three trends: economic rationality; demand integration normative mode of capitalist production by instrumentalization of workers, the emergence of a working class identity through collective action. From the second half of the twentieth century, appear new modes of production and management that provoke significant changes in the working world globally. The work and (or) their lack become objects of dissatisfaction, even of suffering. The work enters in crisis. The same trends may be observed in Brazil. Over the past thirty years, they develop varied forms of informal work, including in the field of economic solidarity, as a response to the "apartheid" social workers and the deep economic fracture of Brazilian society. The concern in this article is to seek to find out to what extent the work today can build the worker as a social subject and become the founding experience of social identity and collective action, discussion that covers historical aspects theoretical and empirical.

Key-words: identity, subjectivity, social experience; relationship to work.

\section{INTRODUÇÃO}

Durante muito tempo concentrada no aspecto técnico do trabalho, a Sociologia do Trabalho, por volta dos anos 60 do século $\mathrm{XX}$, intensificou sua preocupação com o elemento humano desse universo: o operário. Entendeu-se, tanto na França (Friedmann, 1963; Touraine, 1966) quanto na Inglaterra (Escola de Cambridge: Goldthorpe, 1972) que, estudando o operário, se compreenderia melhor sua inserção na sociedade. Perspectiva já presente na Escola de Chicago desde o final dos anos 50, quando Everett Hughes ampliava o conceito de trabalho à vida profissional e passava da noção de operário à de trabalhador inserido num amplo leque de relações e identificações. Operou-se, desse modo, uma transição “da Sociologia do Trabalho até a Sociologia do Trabalhador" (Durand; Weill, 1993, p. 
366). Hoje, ao lado de uma abordagem "clássica" que privilegia a atividade assalariada geradora de riqueza material (Toledo, 2011), a Sociologia do Trabalho procura ampliar seu campo de estudo à descoberta do meio ambiente social e econômico do trabalhador e seus múltiplos vínculos sociais; leva em conta a diversidade das formas de trabalho e de investimentos do trabalhador dentro e fora do seu espaço de atuação; assenta-se nas noções de cultura (Sainsaulieu, 1988), identidade como itinerário pessoal e profissional do trabalhador (Dubar, 1991), experiência (Dubet, 2002) e solidariedade (Laville, 1999), numa visão ampliada do trabalho, criador também de produção imaterial (Toledo, 2011). Enfim, descobre-se uma nova ética do trabalho como "prática reflexiva sobre o lugar do trabalho na vida dos sujeitos" (Nardi, 2002, p. 116).

Neste artigo, procura-se entender o que é o trabalho hoje a partir da descoberta do trabalho "moderno": como foi percebida na época e como pode ser vivida hoje a relação do trabalhador com seu trabalho? Como vai, hoje, o trabalhador elaborar formas de identidade social mediante sua experiência do trabalho? Em outras palavras, em que medida o trabalho, no mundo atual, pode contribuir para construir o trabalhador como sujeito social e tornar-se a experiência fundadora de identidade social e de ação coletiva? Os dois conceitos: identidade social e experiência social serão abordados neste artigo a partir dos trabalhos de Claude Dubar e François Dubet.

\section{AS LÓGICAS DO TRABALHO: DA MODERNIDA- DE ATÉ HOJE}

Para falar da relação do trabalhador com seu trabalho é preciso entender como foi construído o trabalho na modernidade, qual foi a gênese das relações engendradas entre os atores envolvidos, conhecer o papel desenvolvido pelo trabalho na vida dos trabalhadores, entender como as relações de trabalho passaram a tornar-se uma aspiração de relação com o trabalho. ${ }^{2}$

\footnotetext{
${ }^{1}$ Será utilizado o termo "modernidade" para o período que se estende entre o final do século XVIII e o final do século XX

2 Entende-se por relações de trabalho o "conjunto de arranjos institucionais e informais que
} 
Com o advento da modernidade, o trabalho se torna símbolo da vitória da racionalidade e da liberdade: liberdade de empreender, liberdade de vender sua força física, liberdade de produzir riquezas. Teoricamente falando, porque a realidade revela-se rapidamente diferente. É nessa época, contudo, que a sociedade começa a se estruturar em torno do trabalho: ele é fonte de riqueza e de bem-estar e se torna a relação social fundamental.

O trabalho moderno é relação construída, de um lado, no contexto do surgimento e desenvolvimento do capitalismo e no universo da produção coletiva racionalmente organizada e, por outro lado, no âmbito da construção progressiva do assalariamento e de sua posterior degradação. Ele é uma relação fundada em racionalidades diferentes (econômica, político-institucional e social) que não representam "momentos" da história, seqüências, mas lógicas diferentes que se entrelaçam e se completam durante muito tempo, antes de entrar em crise no final do século XX.

A partir destas lógicas, podemos delinear o trabalho sob três aspectos constitutivos: o trabalho como produção, fundado na racionalização da produção de mercadoria e de valor e no assalariamento, gerador de relações profundamente desiguais; o trabalho como problema social e as iniciativas privadas e públicas que tentam responder a uma demanda de justiça; enfim, o trabalho como fator de construção de uma identidade social que pode revelar-se na associação e na ação política. Estes três aspectos constituem um trabalho multifacetado que hoje provoca reações diversas por parte dos trabalhadores, sempre à procura de equilíbrio, reconhecimento e satisfação nos seus tempos de vida: vida profissional, vida social e vida pessoal.

\subsection{O Trabalho-Produção e as Relações Sociais: a racio- nalidade econômica}

No Brasil, assim como nos demais países da América Lati-

modelam e transformam as relações sociais de produção nos locais de trabalho" (Liedke, In:

Cattani, 2002, p. 271). A relação com o trabalho implica a noção de subjetividade e seria a "ma-

neira como os sujeitos vivenciam e dão sentido às suas experiências de trabalho" (Nardi; Tittoni;

Bernardes, In: Cattani, 2002, p. 302).

152| Século XXI, Revista de Ciências Sociai, v.2, nº 2, p.149-173, jul./dez. 2012

ISSN: 2236-6725 
na, a história do trabalho na modernidade 3 é intrínseca à história do binômio desenvolvimento/subdesenvolvimento. A Revolução Industrial aconteceu aqui com mais de cem anos após se desenvolver nos países do Hemisfério Norte. O trabalho como criador de riquezas e de desenvolvimento já tinha uma longa história que, desde o início mostrou-se excludente: pelo tipo de produção engendrada desde a época colonial e pela forma como foi conduzida esta produção. Esta revela uma concepção arcaica do trabalho concretizada numa relação de exploração de uma mão-de-obra que, até hoje, em alguns casos extremos, ainda luta para sair dos padrões escravistas.

No processo de modernização do Brasil as relações capital/ trabalho, parecem terem sido dominadas, durante quase três séculos, pela instrumentalização do trabalho e da mão-de-obra, desde a escravidão até, como é usual no capitalismo, a falta de participação dos trabalhadores na maioria das empresas modernas, apesar da reorganização da produção e das inovações na gestão das pessoas que aparentam ser mais uma forma renovada de exploração do homem e do trabalho. Desde os anos 30, o assalariamento do trabalho e a estruturação do mercado de trabalho tiveram como objetivo a inclusão da produção brasileira no conjunto das nações de capitalismo avançado. No "milagre econômico" almejado durante a ditadura, a riqueza produzida com alto custo social e político continuou concentrada nas mãos de uma elite econômica enquanto o arrocho salarial empobrecia a classe média. Até o final dos anos 90 pouco havia mudado substancialmente. Com as devidas nuanças, é claro, porque do caos social resultante deste processo de modernização desigual cresce, entre os trabalhadores e num contexto de redemocratização política e sócia, um questionamento crítico do modelo de desenvolvimento (prioridade à produção num sistema de trocas desiguais), do destino da riqueza produzida e do sentido exclusivo atribuído ao trabalho como gerador de lucro. A partir deste questionamento começam a aparecer, fora a expansão do trabalho informal, formas alternativas de trabalho e renda de iniciativa popular cujo objetivo é, além da luta

3 Será utilizado o termo "modernidade" mesmo que fosse mais correto falar em "pré-modernidade" para o início do período no caso do Brasil. Esta questão é objeto de debate entre sociólogos latino-americanos como José Mauricio Dominguez (2005) 
contra a miséria e o desemprego, construir outros modos de produção, em franca oposição ao trabalho "clássico".

\subsection{O Trabalho como Problema Social}

O trabalho consagrado, pela Revolução Industrial, como "progresso miraculoso nos instrumentos de produção", logo se configurou como "catastrófica desarticulação na vida das pessoas comuns" (Polanyi, 2000, p. 51), uma questão urgente para ser resolvida. Como amenizar as conseqüências dolorosas do trabalho? De que forma combinar trabalho-produção e tranqüilidade nas relações sociais? Como garantir o progresso e manter a ordem?

No Brasil, a questão das consequências sociais do trabalho sobre os trabalhadores mais fragilizados (pobreza, desordens sociais) e a forma de enfrentá-las vai surgir com a tomada de consciência da condição operária, isto é, quando se começa a valorizar o trabalho, a perceber a diferença entre a riqueza produzida e sua má distribuição, e, enfim, quando se começa a ter uma clara noção da necessidade de poupar o trabalhador para garantir a produção. Esta consciência será tardia. No Brasil colonial, a primeira preocupação com o trabalho se manifesta na luta contra a escravidão e no esforço em vista da sua erradicação. Quando começou a se desenvolver uma produção para o desenvolvimento nacional, o governo populista de Getúlio Vargas inicia uma política trabalhista, mediante uma institucionalização das relações de trabalho como garantia da integração das camadas mais pobres de trabalhadores, da fiscalização das influências ideológicas da época (de um lado, o comunismo, do outro o fascismo) e do controle do operariado. Nos anos 1950-1960, o Brasil passa por uma fase democrática de reformas econômicas e sociais que reforçam as funções distributivas do Estado, até o Golpe Militar de 1964, que leva ao fim os direitos políticos e sociais, à repressão e ao empobrecimento da classe trabalhadora. Nessas alturas, o problema que preocupa as autoridades políticas e os gestores da economia não é a situação dos trabalhadores e suas conseqüências, mas como recuperar, a qualquer custo, o atraso econômico do Brasil 
em relação às nações desenvolvidas. E se, a partir do final dos anos 70 , uma parte do empresariado vai reagir contra as conseqüências desastrosas dessa política, não será pensando na condição específica do operariado, mas em função de sua influência sobre a produção e de sua inserção no mercado internacional.

As respostas ao desemprego, trabalho informal, empobrecimento e exclusão em massa, provocados pelo quadro econômico da "década perdida" de 80 virão de parte da sociedade civil, que começa a se organizar nos campos político e econômico, propondo iniciativas econômicas emergenciais por meio dos empreendimentos da economia popular e/ou economia solidária, apoiada por setores cada vez mais importantes das igrejas e comunidades locais. A partir da década de 90 apresenta-se a resposta patronal: a empresa "social" incorpora a luta contra a pobreza à sua gestão econômica, sem necessariamente rever sua política de desenvolvimento. Por sua vez, os governos civis que se sucederam à ditadura instauraram políticas públicas relacionadas à formação profissional, à proteção contra o desemprego, ao incentivo da expansão do emprego tradicional, mas sem questionar o sistema autoritário das relações de trabalho nem a legitimidade do aval dado à ideologia que sustenta a produção numa perspectiva de desenvolvimento a qualquer preço.

Dessa forma, o Brasil termina o século XX com o crescimento preocupante de uma massa vulnerável, revelada, entre outras coisas, pelas estatísticas da violência, demonstrando que o problema atual não se refere apenas aos efeitos das condições de trabalho, mas também aos resultados da transformação e da falta de trabalho. Se durante muito tempo as conseqüências do trabalho foram consideradas como problema de disciplina e de ordem social, as respostas sugeridas hoje revelam, entre os atores, visões diferentes da sociedade. Entre os detentores do poder, de um lado (governantes e empresariado), elas continuam elaboradas numa lógica de integração que não questiona os fundamentos ideológicos da produção e procura manter o trabalhador numa situação de dependência em relação às formas de flexibilidade do trabalho, imergindo-o numa insegurança social profunda. Para os trabalhadores e suas lideranças, de outro 
lado, a situação pede respostas novas que devem ser elaboradas considerando a demanda popular de reconhecimento social apoiado na transparência das informações sobre a situação econômica e pelo reconhecimento das formas alternativas de trabalho e renda.

\subsection{O Trabalho como construção de identidade coletiva}

Como se constrói uma consciência coletiva de pertencer, como operários, a um grupo social distinto? No Brasil, por parte do trabalhador, a consciência de existir como grupo econômico constituído, como coletivo de trabalho dotado de identidade típica e capacidade de ação, acontece a partir do momento em que a sociedade passa a reconhecer o trabalho e o trabalhador: seja essencialmente por razões econômicas, numa perspectiva de produção, seja por razões ideológicas e/ou humanitárias, numa ótica de integração social. Na primeira metade do século XIX, as ações populares possuíam um baixo nível de organização e, em muitos casos, eram instrumentalizadas pelas elites. Não questionavam nem o modo de produção, nem a dominação patrimonial. A partir da segunda metade do século começa timidamente a aparecer uma nova ideologia do trabalho: a liberdade de iniciativa é essencial para modernizar o país. A reivindicação de autonomia no trabalho encontra sua primeira expressão na luta dos escravos por sua libertação. Na mesma época, na região de São Paulo, surgem entre os trabalhadores imigrados da Itália e da Alemanha, os primeiros grupos de anarquistas com seu projeto de sociedade igualitária, de produção gerida coletivamente pelos trabalhadores e de organização da classe operária. A partir de 1892 eles organizam os primeiros movimentos grevistas no Rio e em São Paulo. Na passagem para o século XX, "a questão do trabalhador imigrante tomará a centralidade que teve a questão do escravo na segunda metade do século anterior" (Gohn, 1995, p. 61). O anarcossindicalismo se consolida e será responsável pelo surgimento do primeiro verdadeiro movimento operário no Brasil, concretizado na formação de associações operárias. Estas passarão a se chamar de "sindicatos" em 1906. Começa a crescer a consciência de uma iden- 
tidade operária, em meio às rivalidades entre influências políticas diversas (socialismo reformista, comunismo e, mais tarde, fascismo). Apesar de ainda mal organizados, os trabalhadores conseguem despertar a ideia de inevitabilidade de uma legislação social.

A revolução de 1930 leva ao poder Getúlio Vargas, que logo ataca de frente a questão das relações trabalhistas no intuito de atingir seu objetivo de modernização do país, mas também de desmobilização das organizações operárias existentes. Ele regulamenta a organização dos sindicatos numa sujeição total ao recém-criado Ministério do Trabalho. A Consolidação das Leis do Trabalho (CLT) vai se tornar o instrumento de regulação das relações trabalhistas, a idealização da colaboração entre trabalhadores e empregadores, o princípio do projeto de sociedade salarial. A grande massa de trabalhadores sem qualificação entende ser um benefício ter garantias legais protegendo salário e emprego, ${ }^{4}$ mas a ação coletiva dos trabalhadores é encaminhada para a burocratização. O movimento sindical, de órgão de reivindicação social e guardião de uma cultura de classe, vê parte de suas organizações tornarem-se administradoras de serviços sociais. Posteriormente ao Golpe de 1964 e com o começo dos "anos de chumbo", a única forma de ação autorizada para os sindicatos que não foram fechados é o assistencialismo. A partir de 1975, os sindicatos voltam a enfrentar o regime militar. Novas lideranças surgem: nasce o "novo sindicalismo" e, na década de 80, a Confederação Geral dos Trabalhadores (CGT) e a Central Única dos Trabalhadores (CUT).

A partir dos anos 90, o movimento dos trabalhadores, nascido no trabalho industrial tradicional, tem muitas dificuldades de ajustar-se às mudanças tecnológicas e sociais do mundo do trabalho. A credibilidade dos sindicatos como movimento de emancipação dos trabalhadores perde terreno, substituído por movimentos e organizações da sociedade civil que cristalizam a demanda cada vez maior de reconhecimento dos direitos fundamentais de diferentes categorias de trabalhadores (trabalho das crianças, o trabalho escravo, as mulheres no mercado do trabalho, o movimento dos trabalhadores

\footnotetext{
${ }^{4}$ A legislação social instaura o salário mínimo e a Carteira de Trabalho.

157| Século XXI, Revista de Ciências Sociai, v.2, n² 2, p.149-173, jul./dez. 2012
} 
sem-terra/MST). Cresce uma nova classe de trabalhadores que, empurrados pela necessidade, encontram em novas formas de trabalho a autonomia e o sustento.

Desta forma, o trabalho que se desenvolve na modernidade, no contexto da empresa capitalista, produz uma sociedade desigual que, em vez de valorizar os seres humanos nas suas capacidades criativas, como donos de si, como seres autônomos, mantém a maioria deles numa situação de sofrimento. O trabalho moderno se desenvolve no cruzamento da racionalidade econômica (prioridade à produção num sistema de troca desigual), da perspectiva de integração, como meio de resolver o problema social que se tornou o trabalho, mas também da luta para a emancipação, fruto da construção progressiva de uma identidade social entre os trabalhadores. Mas este quadro não deixa de revelar um mundo do trabalho em que as relações sociais são submetidas à conivência entre o sistema político e o sistema econômico, que traduzem o trabalho como uma liberdade vigiada e que descobrem um trabalhador vítima de "apartheid", de segregação social, de instrumentalização.

Atualmente, neste início de um novo milênio, se o trabalho ainda é atividade produtiva, esta atividade não só vai além de um "fazer" técnico parcelado e especializado, como também se dilui em relações sociais que acontecem dentro e fora do ambiente de trabalho. Novas tecnologias (TICs), novos tipos de produção (produção imaterial $^{5}$ ), novas formas de regulação do trabalho e de controle (individualização da relação de trabalho), a quase universalização do assalariamento (que não reflete mais uma posição social clara e torna confusas as relações de dominação) são elementos que questionam a visão clássica do trabalho. É toda uma concepção da identidade pelo trabalho que está se diluindo. O trabalho, hoje, não representa mais uma etapa da vida na qual se ingressa para adquirir identidade e reconhecimento social, mas um processo cheio de incertezas, de dúvidas individuais e coletivas. O trabalho, para quem ainda tem, pode, muitas vezes, gerar sofrimento, individualismo, discriminação

5 “...transformación y generación de objetos puramente simbólicos. La producción inmaterial es aquella en la que el producto no existe separado de la própria actividad de producir..." (TOLEDO, 2011,p.15) 
e exclusão; o trabalhador procura outros campos de realização pessoal, de relacionamentos e de conflitos, o que fez surgir uma literatura defendendo a idéia do fim do trabalho (Meda, 1995). O trabalho e sua ausência são objeto de insatisfação, de questionamentos e de aspirações não alcançadas: há uma demanda de autonomia e de verdadeira responsabilização no trabalho, uma aspiração para mais justiça e para uma melhor repartição do trabalho (e não apenas de seus frutos), uma demanda de realização e de reconhecimento individual e social. O trabalhador hoje se define a partir das vivências adquiridas no trabalho e fora dele e não mais, como em outros tempos, a partir de uma identidade de categoria profissional, num mundo do trabalho reconhecido em crise.

\section{A CONSTRUÇÃO DO SUJEITO NO TRABALHO: ENFOQUE TEÓRICO 6}

Identidade, experiência e subjetividade são temas recorrentes quando a Sociologia aborda a questão das relações do trabalhador com seu trabalho. Sem entrar na complexidade dos conceitos e seu desenvolvimento histórico, abordar-se-á aqui apenas a perspectiva de sua construção no âmbito do trabalho no mundo de hoje.

Apesar de não ser nova, é Alain Touraine que reaviva e aprofunda a reflexão sobre a idéia do Sujeito a partir da crítica da modernidade e do questionamento sobre o "viver juntos". Frente à decomposição da sociedade atual, à dissociação entre o instrumental e o simbólico, o Sujeito aparece como uma oportunidade, individual e coletiva, de recomposição da vida social e política. O Sujeito, esta disposição do indivíduo a ser ator social, é resistência, é recusa, é liberdade. Ele é "procura, pelo indivíduo ele mesmo, das condições que permitem que ele seja ator da sua própria história” (Touraine, 1997, p.78) ${ }^{7}$. É luta pelo direito a uma existência individual, é dar sentido a suas próprias experiências, é uma disposição para dizer

\footnotetext{
${ }^{6} \mathrm{~A}$ referencia aqui dá prioridade às obras fundadoras do estudo dos conceitos apresentados: DUBAR, "A socialização. Construção das identidades sociais e profissionais" (1991) e DUBET, "Sociologia da experiência" (1994).

${ }^{7}$ Tradução nossa
}

159| Século XXI, Revista de Ciências Sociai, v.2, nº 2, p.149-173, jul./dez. 2012 
"eu", para se reconhecer e ser reconhecido, o que não acontece sem tormento. $\mathrm{O}$ desejo de subjetivação (tornar-se sujeito) não é procura da diferença, mas "afirmação do indivíduo como ator das orientações e transformações da vida social” (id. p. 81). É a razão pela qual Touraine vincula a idéia de Sujeito à ação coletiva: "A idéia de Sujeito... se faz presente em todo lugar onde se manifesta uma ação coletiva de construção de um espaço ao mesmo tempo social, político e moral de produção da experiência individual e coletiva" (id. p. 102).

Entender esta noção por demais abstrata de Touraine é fundamental para tentar esclarecer os conceitos de identidade e experiência e em que medida estes podem contribuir a transformar a relação do trabalhador com seu trabalho em meio à crise atual.

Carregado de história, sobretudo no campo da filosofia, o conceito de identidade volta a ser objeto de estudos sistemáticos por volta dos anos 1950 nos Estados Unidos com a Escola de Chicago e nos anos 1970 na França, inicialmente no campo da psicologia e da antropologia e depois na sociologia, quando começam a brotar reivindicações identitárias por parte de minorias culturais, em meio à efervescência de um mundo do trabalho em plena mutação. Impõe-se a idéia que é tarefa do próprio indivíduo de construir-se: a identidade não é um dado, uma determinação, mas uma busca, uma construção.

Claude Dubar elabora um esquema de interpretação da dinâmica das identidades profissionais a partir desta perspectiva. Segundo ele, a construção da identidade é fruto de socializações sucessivas e/ou simultâneas, é um processo dinâmico e relacional (ao mesmo tempo individual e coletivo) de construção de um projeto que se inscreve na continuidade e num espaço determinado. Assim, não faria sentido falar em identidade pessoal ou identidade coletiva, categorias que não são mais pertinentes, mas em identidade social, isto é: socialmente reconhecida (Dubar, 1991). A identidade é resultado de dois processos opostos: um processo de atribuição e um processo de incorporação. No primeiro, a atribuição de identidade, que ocorre nos sistemas de ação, implica relações de força entre indivíduos e sistemas. É o que o autor chama de identidade virtual. No segundo processo, a incorporação de identidade pelos indivíduos acontece 
nos grupos de referência ou durante sua trajetória pessoal e social, e é chamada por Dubar de identidade real. Para reduzir a oposição ou a distância entre estes dois processos, os próprios indivíduos vão criar estratégias de negociação, de construção conjunta de sua identidade: entre, de um lado, uma transação objetiva, relacional entre o indivíduo e os outros (indivíduos ou sistemas) para ajustar uma identidade para si (auto-atribuída ou almejada) a uma identidade para os outros (atribuída ou exigida nos sistemas de ação) e, por outro lado, uma transação subjetiva, biográfica, entre identidade herdada dos grupos de referência e identidade pretendida (projetos pessoais) para assimilar a identidade para os outros à identidade para si. No primeiro caso, estamos numa lógica de reconhecimento pelo sistema que pode levar à adesão ou ao conflito; no segundo caso, estamos numa lógica instrumental, que pode levar à continuidade ou ruptura com o grupo de referência. Assim, segundo Dubar, a identidade seria uma articulação entre estas duas transações, entre a vertente relacional e a vertente biográfica dos indivíduos. Em conseqüência, a identidade é o "resultado estável e provisório, individual e coletivo, subjetivo e objetivo, biográfico e estrutural, de vários processos de socialização" (Id. p.113) que pode concretizar-se em várias combinações, em vários tipos identitários, em várias categorias de identificações. Assim sendo, o autor ressalta o fato que o campo do trabalho e do emprego, enraizados na formação, desempenham um papel primordial na construção identitária.

Dubet, por sua vez, inicia sua reflexão pela constatação da fragmentação do social em múltiplos paradigmas que são a expressão da decomposição da perspectiva clássica da sociedade: não existe mais, na sociedade atual, um princípio único de coerência. Todo "conjunto social" no qual se movimenta o ator é uma justaposição, um arranjo entre três grandes tipos de subsistemas autônomos, mas que se entrecruzam: comunidade, mercado e sistema cultural. Este último é "a definição de uma criatividade humana que não pode ser reduzida à tradição ou à utilidade" (Dubet, 1994, p. 110). Cada um desses sistemas é fundado em uma lógica de ação própria: a integração, quando o ator é definido pelos seus vínculos na comunidade; a 
estratégia, quando ele é definido por seus interesses num mercado; a subjetivação, quando o ator é definido por sua reflexividade, isto é, sua capacidade de elaborar uma reflexão crítica sobre si mesmo e sobre as ações realizadas. Estas lógicas são autônomas e não hierarquizadas. Na lógica da integração, a identidade do ator é "adscrição", submissão pela atribuição e interiorização de valores institucionalizados por meio dos papéis, tornando ele um "ser social". O ator é reconhecido na medida em que está integrado. Na lógica estratégica, a identidade é um recurso, um meio para atingir determinados fins num espaço de intercâmbio, num mercado concorrencial (mercado não só do ponto de vista econômico, mas em todas as atividades sociais). A identidade é vinculada ao conceito de status e não mais ao de papel, no sentido em que o ator é reconhecido na medida em que pode, em que tem recursos para influenciar os outros a partir da posição que ocupa. Na lógica da subjetivação, o ator "é" na medida em que é capaz de se distanciar de si mesmo e da sociedade. Sua identidade é definida como um engajamento na procura do "ser sujeito", "permitindo-lhe perceber-se como o autor de sua própria vida" (id. p.128). A identidade, todavia, pode também ser definida como um "desengajamento": "a identificação com uma definição cultural do sujeito impede a adesão total à comunidade ou ao mercado" (id. p. 128). A identidade é, assim, sua capacidade de distanciamento.

A experiência social, conceito central para Dubet, seria então, uma elaboração reflexiva, crítica, fruto de uma socialização num contexto particular e se torna uma maneira de abordar o real. É uma combinação de lógicas de ação articuladas pelo ator e a identidade social não é um "ser", mas um "trabalho", uma construção (p. 16) mediante estratégias de resposta às diferentes lógicas presentes no "conjunto social", trabalho realizado nas tensões e no conflito. Como acontece essa construção? Num primeiro momento, o ator passa por um sentimento de estranhamento frente às tensões que existem entre os diferentes papeis desenvolvidos por ele e frente às diversas lógicas de ação encontradas no seu "conjunto social". Ele tem o sentimento de não corresponder aos papeis que se espera dele. Diante dessa situação, o ator tenta definir suas afinidades, seus vínculos. É a construção de 
uma “identidade-problema”, a "apresentação de si”, identidade feita de tensões e sofrimentos. Num segundo momento o ator tenta reconstruir esta experiência como sendo sua, questionando o seu sentido: afinal, ela lhe diz respeito. O que está em jogo é a "capacidade de dizer eu" (p. 184): o que é que eu quero? A partir do estranhamento e por meio de um movimento de distanciamento crítico ele procura construir uma “identidade social profunda" numa manifestação de autonomia. É um movimento de subjetivação que se opera no conflito, na oposição à alienação ${ }^{8}$. É nesta atividade que ele procura se construir como sujeito: "o sujeito se constitui na medida em que ele precisa construir uma ação autônoma e uma identidade própria em razão da pluralidade dos mecanismos que o aprisionam e das provações que ele enfrenta" ( $p$. 254). Enfim, ele pode recompor sua identidade antes dissociada, dar sentido a suas condutas no engajamento coletivo, o que Dubet chama de ação política ou de "introdução da subjetivação nas relações sociais", de "subjetividade afirmada" (p. 186).

Dubet vai aplicar seu esquema de análise a vários campos, mas, sobretudo, no trabalho não clássico de produção imaterial no qual ele destaca o "trabalho sobre o outro", com o objetivo de entender "como nossa sociedade fabrica indivíduos e sujeitos no quadro de uma atividade profissional organizada" (Dubet, 2002, p. 13) e com o objetivo de entender como os trabalhadores estudados constroem sua experiência de trabalho. Em todos os casos analisados, o ator-trabalhador é central: ele vive uma experiência que o leva a formas de engajamento ou desengajamento do trabalho, segundo sua maior ou menor capacidade de articular as diversas lógicas de ação presentes na organização. Essas estratégias podem revelar diferentes formas de comprometimento com a organização e de competência no trabalho, isto é, as maneiras como pode se tornar ator de sua própria vida e dar sentido ao seu trabalho.

Como se pode constatar, existem vários pontos de convergência entre Dubar e Dubet. Ambos consideram a identidade social como uma construção-relação entre atores e os espaços estruturados

${ }^{8}$ No sentido dado por Dubet a este conceito: “ privação de capacidade de ser sujeito" (1994, p. 133). É um conjunto de condutas acompanhadas de sofrimento, de sentimento de destruição de si provocado pela dominação social. 
da ação9 . Esta construção, resultado de uma experiência social, se realiza sob influência da(s) socialização(ões) e leva a uma tipologia das formas de ação a partir de lógicas distintas e de estratégias diferentes. Também é um "trabalho" que realiza um ator-sujeito na oposição, no conflito e no sofrimento. Para ambos, enfim, trata-se de um a ação de recomposição da vida social, seja na construção de um projeto profissional que legitima uma identidade socialmente reconhecida em meio à transformação do mundo industrial (Dubar), seja na reconstrução e compreensão dos conflitos e desafios que estruturam a vida social através da singularidade das ações dos atores - sua experiência social - numa sociedade onde subjetividade dos indivíduos e objetividade do sistema se afastam, colocando na ordem do dia a pergunta do "viver juntos".

Assim podemos observar o quanto forte é o vínculo entre identidade e subjetividade. Se na modernidade identidade era sinônimo de identificação a um coletivo de vida ou de trabalho, hoje, a redefinição do conceito acentua o problema da especificidade e da diferença na construção de si e na transformação da sociedade em campos diversificados: político (identidades nacionais), sociológico (poder e dominação a partir de papeis e status diversos), psicológico (identidade e personalidade) e antropológico (identidade e cultura), campos que não são estanques. Hoje, a volta do interesse para o conceito, afinada com o retorno do interesse para o ator-sujeito, leva certos autores a acreditar que "estamos na era da identidade" (Halpern, 2004), mas sofre também críticas sobre o modismo do conceito (Kaufmann, 2004). Entretanto, existe uma convergência sobre a concepção de identidade como expressão do "sujeito reencontrado", do universo subjetivo como construção da realidade numa interação constante com o outro e com seu contexto de vida (Costalat-Founeau, Lipiansky, 2008). Pesquisas realizadas pelos autores abordados aqui demonstraram a operacionalidade dos conceitos quando se trata de questionar o mundo do trabalho ${ }^{10}$.

\footnotetext{
${ }^{9} \mathrm{O}$ que não deixa de ser importante em termos de implicações metodológicas para a pesquisa.

${ }^{10}$ Dubet: "Le déclin des instituitions" (2002); "Injustices. L'expérience des inégalités au travail" (2006). Dubar: "Analyser les entretiens biographiques: l'expérience des récits d'insertion" (1997); "Sociologie des professions" (2005).
} 


\section{PODE O TRABALHO CONSTRUIR O TRABA- LHADOR COMO SUJEITO SOCIAL?}

O estudo dos conceitos de identidade e de subjetividade permite explorar novos modos de pensar e agir num trabalho em transformação. Vários assuntos podem ser estudados nesta perspectiva. Entre eles: a autonomia no trabalho, as novas formas de dominação, as conseqüências sobre o trabalhador da responsabilização nas performances e da individualização da relação de trabalho (novas formas de sofrimento, suicídios, estresse, etc.); o cotidiano do trabalho e seu impacto na vida do trabalhador (gestão dos tempos sociais: tempos pessoais - lazer, família - e profissionais); formas e sentidos da ação coletiva a partir do trabalho (dentro ou fora do quadro do sindicalismo?). Por outro lado, o trabalho "não clássico" criador de riqueza imaterial e/ou simbólica se apresenta sob formas diversificadas: trabalho assalariado, formal, mesmo que com características novas (TICs, serviços orientados para as pessoas), mas também trabalho informal, precário e, se expandindo muito no Brasil, o trabalho atípico que representa a economia solidária. Cada vez mais estudos introduzem a variável "subjetividade" na análise do comportamento individual e coletivo no trabalho formal, enquanto trabalho informal ou solidário, considerando-se sua contribuição limitada ao desenvolvimento da economia nacional, parecem marginalizados. Entretanto, pode-se questionar se neles também se encontrariam manifestações individuais e coletivas de aspiração ao reconhecimento humano e profissional, à criação de uma relação ao trabalho geradora de identidade social, fundada numa experiência social específica?

A partir deste questionamento, foi realizada uma pesquisa ${ }^{11}$ cujo objetivo era estudar as transformações que ocorrem na relação entre o trabalhador e seu trabalho nas organizações de economia solidária $^{12}$, analisando o trabalho sob as dimensões de experiência social,

${ }^{11}$ Wautier, A.M. “A relações de trabalho nas organizações de Economia Solidária (Um paralelo Brasil-França)", 2005.

${ }^{12}$ Trata-se de um setor de atividades no qual são produzidos bens e serviços que nem sempre podem ser quantificados, mas que são fundados na solidariedade (seja no campo da reinserção social, da educação popular ou da filantropia) e em que se reivindica a criatividade e a originalidade de um trabalho "outro", economicamente mais justo e fonte de emancipação humana.

165| Século XXI, Revista de Ciências Sociai, v.2, nº 2, p.149-173, jul./dez. 2012

ISSN: 2236-6725 
constitutiva de identidade, e de socialização para e pela solidariedade, dentro e fora do trabalho. Em outras palavras, procurou-se reconstituir processos e entender o sentido mais geral da construção de sua ação pelos trabalhadores, entender as singularidades do engajamento dos atores, seu impacto sobre a relação do trabalhador com seu trabalho, com a organização e a sociedade. Tratava-se de investigar empiricamente a possibilidade de construção de um trabalho "solidário" em organizações no Brasil (Porto Alegre) e na França (Paris). O estudo dos conceitos de identidade e subjetivação apresentados aqui levou à hipótese segundo a qual o trabalho, tal como se realiza nas organizações de economia solidária, seria uma experiência social suscetível de estimular novas formas de relações sociais, por meio de uma socialização fundada na solidariedade. Essas relações sociais abrangeriam tanto as relações com o trabalho quanto as relações com a sociedade. Esse trabalho peculiar, ou seja, o trabalho solidário, tornar-se-ia possível graças a uma eventual capacidade de subjetivação do trabalhador, uma aptidão em se construir como sujeito e construir criticamente a realidade. Esse trabalho seria concretizado por meio de uma socialização não reduzida à aquisição de práticas profissionais, mas que visaria às práticas coletivas de inserção na sociedade; socialização que não trataria apenas de adquirir uma competência profissional, um "instrumento" de trabalho, mas também uma competência social "cidadã", uma nova forma de sociabilidade.

Para tanto, foi importante, entender não só como o trabalhador vê a organização, suas práticas, suas exigências, mas também como ele se situa nela, quem ele é, o que ele faz, como percebe o impacto do seu trabalho para a organização e para ele mesmo, a fim de compreender os mecanismos de construção de sua experiência de trabalho. Procurou-se esclarecer o que seria trabalhar numa organização de economia solidária a partir de duas dimensões: uma, subjetiva, considera o trabalho como experiência social do trabalhador; outra, mais institucional, parte do princípio da socialização, mas numa interpretação típica da economia solidária: a socialização para e pela solidariedade. As perguntas feitas aos trabalhadores, os temas abordados, procuraram descobrir informações sobre a manei- 
ra como ele elabora um conhecimento crítico sobre sua organização, sobre as atitudes que tem ao tentar resolver o dilema existencial: viver e trabalhar. A apresentação do seu discurso seguia dois eixos: a relação do trabalhador com o trabalho "para" a organização e com o trabalho "para ele". No primeiro caso, tratava-se do trabalho que dá um estatuto e um meio de viver: é o conjunto de condições objetivas que a organização oferece para o exercício de um "saber fazer", de uma atividade profissional, espaço de construção das relações de trabalho. Este trabalho "para" a organização fornece informações sobre as lógicas de ação que nela predominam e como essas lógicas se inscrevem em relações sociais concretas nas quais afloram as exigências da socialização. Aqui, o trabalhador deu sua definição da organização e suas lógicas de ação. No segundo caso, tratava-se do trabalho vivenciado pelo indivíduo: é o olhar que ele põe sobre o lugar ocupado pelo trabalho na sua vida, o sentido que lhe atribui; é o trabalho fonte de engajamento individual e coletivo, fonte de investimento; é o que proporciona a construção do indivíduo e de sua identidade na relação com o trabalho. Indica ainda as estratégias desenvolvidas pelo trabalhador para responder à demanda da organização e como ele vive e constrói suas relações de trabalho dentro e fora da organização. Aqui, o trabalhador deu informações a respeito da construção de sua experiência. Foi nesta etapa de distanciamento crítico, de subjetivação, que ele se questionou sobre o que queria exatamente. Neste balanço do que parece positivo e negativo, o trabalhador informou como ele ia proceder na reconstrução de uma identidade, de uma sociabilidade, no quadro do seu trabalho.

Assim, nas organizações da economia solidária estudadas, formas de explicação do social e de procura de legitimação da ação desenvolvida expressaram-se em lógicas específicas presentes em cada uma delas: adesão aos valores da economia solidária, excelência no trabalho realizado, reconhecimento da legitimidade da singularidade dos trabalhadores e de uma nova ética do trabalho. Foi o rumo dado à socialização, porém, visando ao mesmo tempo à dimensão profissional e à dimensão de participação nos valores e na ação da organização (que também são formas de mobilização) 
que influenciou a construção das relações sociais em seu interior. Viu-se que a organização socializa para uma ação que se insere em relações, ao mesmo tempo de produção, políticas e afetivas, ação que tinham um objetivo mais ambicioso: humanizar as relações na sociedade, apoiando-as num referencial outro que não apenas utilitarista, uma sociedade na qual o trabalhador da economia solidária seria o porta-voz desse novo credo.

Acontece que a construção desse sonho apresentou falhas, reveladas na percepção que os próprios trabalhadores têm de sua organização e seu projeto, sem por isso deixarem de reconhecer sua legitimidade. Não só as lógicas da ação, na sua heterogeneidade, desorientavam os trabalhadores, não só a socialização não conseguia mobilizar de maneira unânime, mas ao que parece, as relações sociais reproduziam, nas organizações de economia solidária, mecanismos de dominação herdeiros dos vícios de gestão que se encontram em outros setores de atividade (empresas capitalistas, serviços públicos) apontando para desigualdade e alienação. Como, então, iriam reagir os trabalhadores, diante de tal defasagem e das tensões geradas?

Além de uma mera percepção do que é a organização, o discurso dos trabalhadores revelou também uma "atividade cognitiva", uma reflexão que era sua compreensão da organização e do seu lugar nela. Esta reflexão contribuiu para a construção de atitudes e posicionamentos que iriam orientar seu trabalho. Entre sofrimento, críticas e tensões, o trabalhador procurou um modus vivendi, tentou encontrar as atitudes mais adequadas para que seu projeto pessoal, suas expectativas no trabalho sejam compatíveis com o que se esperava dele na organização e para reduzir a dificuldade que ele tinha para se ajustar às lógicas de ação que nem sempre lhe pareciam conciliáveis. Dito de outro modo, ele desenvolveu estratégias que poderiam combinar interesses pessoais e interesses coletivos, motivações individuais e ação coletiva da organização, seja na adesão, seja num engajamento calculado ou numa participação adequada a seu próprio projeto e que, em caso de não-adequação, poderia se tornar desengajamento e ruptura. Pôde-se assim descobrir como conflitos, tensões e sofrimento dos trabalhadores, sempre confrontados com a vontade 
de realizar seu projeto de trabalho, refletem sua difícil tarefa de subjetivação, isto é, de construção de si mesmos como sujeitos críticos, movidos pelo desejo de realizar-se como trabalhador e como pessoa e de serem reconhecidos como tal e como sujeitos sociais movidos pelo desejo de tomar parte na construção de outra maneira de trabalhar, de outra maneira de viver na sociedade. Pôde se descobrir que a possibilidade de autodeterminação, mesmo no conflito, e não apenas de autonomia no trabalho, ainda não parece generalizada no trabalho solidário. A análise das diferenças entre o que os mentores da economia solidária idealizam e a vivência cotidiana dos trabalhadores permitiu se aproximar de uma realidade múltipla e complexa expressa na diversidade das suas experiências ${ }^{13}$.

Enfim, pode-se chegar à conclusão que o trabalho solidário representa, para os entrevistados, uma experiência social original na medida em que eles são capazes de lançar um olhar crítico sobre a organização e seu projeto, de expressar seu estranhamento, de enfrentar os conflitos e de encontrar um modus vivendi, uma conciliação entre projeto pessoal e projeto coletivo. Processo que, para alguns, pode ser interrompido ou bloqueado, seja por fatores pessoais ou institucionais. Quem não pode tomar essa distância crítica em relação a si mesmo, a seu trabalho e à organização, demonstra uma tendência a encarar seu trabalho como fonte de rendimento, sem maior engajamento nem dentro nem fora da entidade. Parece correto afirmar que uma nova relação subjetiva com o trabalho está em fase de elaboração. Essa construção conjunta se expressa nas relações sociais predominantes na organização, que podem ser mais afetivas, mais racionais ou mais políticas, e representa uma forma de engajamento, uma tentativa de o trabalhador salvar seu projeto pessoal e de encontrar um sentido no seu trabalho, apesar de manifestações disfarçadas de dominação e apesar das ambigüidades do trabalho. A socialização solidária, entretanto, não consegue construir de maneira significativa "novas" relações sociais, e ainda provoca a

${ }^{13}$ Nas diferentes organizações estudadas, encontram-se representações que convergem, indicando lógicas de ação semelhantes, encontram-se traços típicos como também maneiras diferentes de tratar temas sensíveis, o que permite estabelecer algumas "regularidades" no discurso dos trabalhadores e elementos de comparação entre organizações brasileiras e francesas. 
resistência dos trabalhadores. De um lado, no trabalho, faltam formas adequadas de concretização do sonho de um trabalho "outro", particularmente na gestão cotidiana e permanecem traços herdados de uma relação de trabalho dominada pela ideologia capitalista. Por outro lado, a ampliação de novas relações sociais para o âmbito da sociedade ainda fica restrita a uma minoria de trabalhadores. $\mathrm{O}$ trabalho solidário como experiência de construção de uma subjetividade assumida existe certamente nas organizações de economia solidária, mas não de maneira generalizada e nem sempre incentivada. E perguntas continuam sem respostas: existiria, na economia solidária, uma verdadeira contestação do trabalho tal como foi engendrado pela modernidade, o que representa o fundamento mesmo do discurso oficial? Ou continua ele, apesar dos projetos mais bem implantados e mais bem-sucedidos, fator de produção de riquezas, instrumento de poder, elemento de integração social em termos de ordem social e de consumo?

\section{CONCLUSÃO}

Se o trabalho hoje continua a se impor como uma evidência na vida dos trabalhadores, seus aspectos constitutivos (o trabalho produção, o trabalho problema social e o trabalho como identidade coletiva), sofreram transformações significativas. Não só novas tecnologias provocaram novas formas de exclusão e injustiça, mas as relações de trabalho e as formas de identificação do trabalhador a uma classe e a um coletivo de trabalho mudaram muito. A crise do final do séc.XX levou a uma reflexão sobre novas insatisfações e novas reivindicações no mundo do trabalho. Foi o "retorno do ator" e sua aspiração a ser sujeito (Touraine), a ser reconhecido na sua especificidade e na sua diferença. Novas formas de gestão do trabalho não conseguiram apagar uma demanda crescente de participação e autonomia em setores que não se limitavam ao trabalho industrial e ultrapassavam a capacidade de reação do sindicalismo tradicional.

A sociologia entrou em cena para propor uma leitura destas mudanças a partir de uma releitura dos clássicos. Conceitos de so- 
cialização, ação social, subjetividade e identidade voltaram a ser o centro das atenções e das pesquisas, inclusive no campo do trabalho. Os autores abordados aqui, Dubar e Dubet, não são as únicas referências teóricas para abordar a questão da relação do trabalhador com seu trabalho, mas talvez os que mais sublinharam o vínculo subjetividade - experiência social - identidade social na construção do trabalhador como sujeito social. As pesquisas mostram que esta equação não resolve os problemas de relação no trabalho, mas permite entender melhor os mecanismos de construção de si do trabalhador e das novas formas de ação coletiva para enfrentar estes problemas apesar da persistência de formas de dominação e de injustiça. A análise do trabalho em termos de experiência social abre numerosas perspectivas para compreender formas de trabalho que parecem implicar de maneira significativa a subjetividade do trabalhador e uma representação diferenciada da sociedade. A experiência social constitui assim "uma maneira singular de fabricar a sociedade" (Dubet, 2009, p.327), que é, antes de tudo, o produto dos atores, cada individuo representando "a unidade elementar da vida social, uma partícula cada vez mais ativa e mais ativada” (Id. p.283).

\section{REFERÊNCIAS}

CATTANI, Antonio David (Org.). Dicionário crítico sobre trabalho e tecnologia. Porto Alegre: UFRGS, 2002.

COSTALAT-FOUNEAU, A.M. et LIPIANSKY, E.M. Le sujet retrouvé. Connexions, no. 89, 2008.

DOMINGUEZ, José Mauricio. Sociologia brasileña, Latinoamérica y la tercera fase de la modernidad. Estúdios Sociológicos, Vol. 23, nº.68 (MayAug. 2005) pp 591-610.

DUBAR, Claude. La socialisation. Construction des identités sociales et professionnelles. Paris: Armand Colin, 1991.

DUBET, François. Sociologie de l'expérience. Paris: Seuil, 1994. 
. Le déclin de l'institution. Paris: Seuil, 2002.

. L'expérience sociologique. Paris: La Découverte, 2007.

. Le travail des Sociétés. Paris: Seuil, 2009.

DURAND, J.P.; WEIL, R. Sociologie contemporaine. Paris: Vigot, 1993.

FRIEDMANN, Georges. Où va le travail humain? Paris: Gallimard, 1963.

GOHN, Maria da Glória. História dos movimentos e lutas sociais. A construção da cidadania dos brasileiros. São Paulo: Loyola, 1995.

GOLDTHORPE, John et al. L'ouvrier d'abondance. Paris: Seuil, 1972.

HALPERN, Catherine. Faut-il en finir avec l'identité? Sciences Humaines, $\mathrm{n}^{\mathrm{o}} .151$, Juillet, 2004.

LAVILLE, Jean-Louis. Une troisième voie pour le travail. Paris: Desclée De Brouwer, 1999.

LIEDKE, Elida Rubini. Relações de trabalho. In: CATTANI, Antonio David (Org.). Dicionário crítico sobre trabalho e tecnologia. Porto Alegre: UFRGS, 2002. p. 271-273.

MEDA, Dominique. Le travail. Une valeur en voie de disparition. Paris: Aubier, 1995.

NARDI, Henrique Caetano. Ética do trabalho. In: CATTANI, Antonio David (Org.). Dicionário crítico sobre trabalho e tecnologia. 4. ed. Petrópolis: Vozes; Porto Alegre: UFRGS, 2002a. p.116-122.

; TITTONI, Jaqueline; BERNARDES, Jefferson Souza. Subjetividade e trabalho. In: CATTANI, Antonio David (Org.). Dicionário crítico sobre trabalho e tecnologia. 2002b. p.302-308.

POLANYI, Karl. A grande transformação. As origens de nossa época. $2^{\mathrm{a}}$. ed. Rio de Janeiro: Campus, 2000.

SAINSAULIEU, Renaud. L'identité au travail. $3^{\mathrm{a}}$. ed. Paris: Presses de la Fundation Nationale des Sciences Politiques - FNSP, 1988. 
TOLEDO, Enrique de la Garza (Org.). Trabajo no clásico, organización y acción colectiva. Tomo I. Mexico: Universidad Autónoma Metropolitana; Madrid: Plaza y Valdés Editores, 2011.

TOURAINE, Alain. Pourrons-nous vivre ensemble? Egaux e différents. Paris: Fayard, 1997.

_. La conscience ouvrière. Paris: Seuil, 1966.

WAUTIER, A. M. As relações de trabalho nas organizações de Economia Solidária (Um paralelo Brasil-França). In: $29^{\circ}$ Encontro Anual da ANPOCS, 2005, Caxambu (MG).

Recebido: 09/11/2012

Aprovado: 17/12/2012 
